\title{
An elasto-viscoplastic model for chalk including suction effects
}

\author{
F. Collin \\ Université de Liège (FNRS, Department ARGENCO), Belgium
}

V. De Gennaro \& P. Delage

Ecole des Ponts, Paris (Université Paris-Est, Navier Institute-CERMES), France

G. Priol

Arcadis, Paris, France

\begin{abstract}
During the six years long Pasachalk project devoted to the mechanical behaviour of high porosity chalks from North Sea oilfields, the constitutive model Pasachalk (Collin et al., 2002) was proposed based on the Barcelona Basic Model (BBM) (Alonso et al., 1990). The approach was based on the similarities found between the oil-water interactions (oil and water being the non wetting and wetting fluid respectively) in oil reservoir chalk and the air-water interactions in unsaturated soils. This approach appeared to be relevant to interpret the subsidence of the seafloor during waterflooding operations for enhanced oil recovery that has been observed in North Sea oilfields (e.g. Ekofisk oilfield). Another important component of subsidence was then related to the creep behaviour of the multiphase chalk (De Gennaro et al., 2003). A modified Pasachalk model was proposed to account for time effects using the framework of Perzyna's viscoplasticity (1964) but without considering suction effects. Based on available experimental results (Priol et al., 2007), a modified version of the viscoplastic Pasachalk model including suction effects is proposed in this paper.
\end{abstract}

\section{INTRODUCTION}

The mechanical behaviour of chalk has been extensively studied since the early eighties, in particular with regard to the behaviour of oil reservoir chalks in the North Sea (Ekofisk oilfield, see Hermansen et al., 2000, Nagel 2001). More recently, the risk assessment of the long-term stability of chalk pillars in mineworkings has been considered. In both situations, two poorly miscible pore fluids of different wettabilities are contained by chalk: water and oil in reservoir chalks and water and air in continental chalks from mines and quarries. In multiphase chalks, the partial saturation can change with time. The water saturation in oil reservoir chalks can increase due to reservoir enhanced exploitation by waterflooding (e.g. Ekofisk oilfield). Water saturation changes in mine chalks can be a consequence of the combined effects of changes in water table and in the hygrometry of the mine.

Like in unsaturated soils, it has been showed that changes in partial saturation have an influence on the mechanical response of chalk, the higher the degree of water saturation, the higher the compressibility and the lower the strength (water weakening effect). In oil reservoirs, mines and quarries, the overburden formations apply long term hydro-mechanical loadings, resulting in creep, a behaviour feature particularly pronounced in chalks.

Some recent experimental and theoretical approaches carried out on partially saturated chalks have confirmed the relevance of some concepts of the mechanics of unsaturated soils to multiphase chalk behaviour, as suggested by Delage et al. (1996). Collin et al. (2002) proposed a modified version of the Barcelona Basic Model (BBM, Alonso et al., 1990) called Pasachalk model to model the behaviour of oil reservoir chalks. This model was extended to include viscoplastic behaviour of reservoir chalk but this latter model did not take implicitly the suction effect into account (De Gennaro et al., 2003). The effects of the oil-water suction on the time dependent behaviour of reservoir chalks has only been partially explored up to now. In this regard, recent findings (Priol, 2005; Priol et al., 2007) from oedometer tests carried out on chalk samples seem to suggest that the delayed strain of chalk is well correlated with the over-stress ratio (i.e. the ratio between the actual stress and the yield stress).

Based on these findings and on other available results, a modified version of the viscoplastic Pasachalk model including oil-water suction effects is proposed in this paper. 


\section{EXPERIMENTAL EVIDENCE OF CREEP IN CHALK}

Priol (2005) and Priol et al. (2007) reported results of oedometer compression tests carried out on Lixhe chalk (an outcrop chalk from Belgium) saturated with oil, with water, partially saturated and dry (Fig. 1). By analyzing the evolution of the creep curves obtained during multiple step loading tests, it was suggested to consider the following rheological law to fit the experimental data:

$$
\frac{e}{e_{o i}}=\beta_{i} t^{-\alpha_{c r}}
$$

where $e$ is the void ratio, $e_{o i}$ the initial void ratio, $t$ the time, $\beta_{i}$ a coefficient accounting for the instantaneous

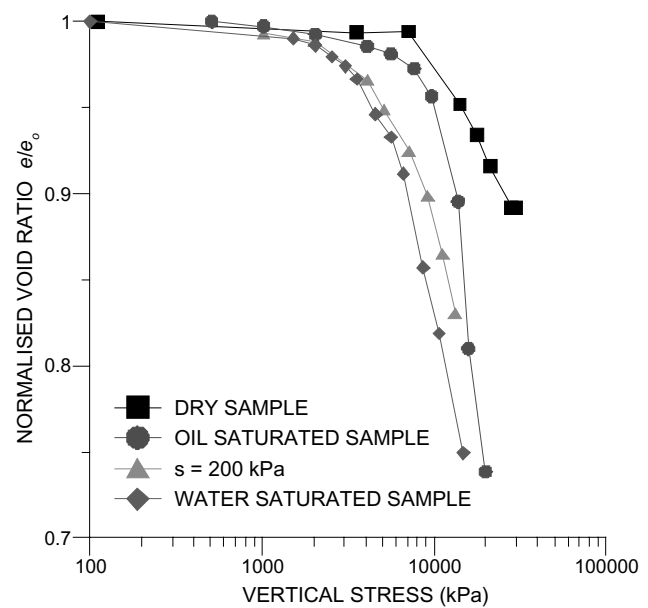

Figure 1. Oedometer compression tests on Lixhe chalk at various saturation states (Priol et al., 2007).

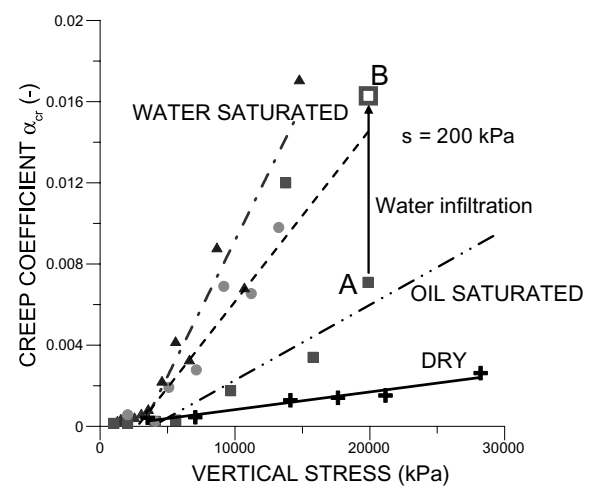

Figure 2. Influence of stress level and suction on the creep coefficient $\alpha_{\mathrm{cr}}$ (Priol et al., 2007). settlement and $\alpha_{c r}$ for the time dependent settlement. The evolution of $\alpha_{c r}$ is directly related to the creep behaviour of chalk (Fig. 2). One can observe that the amount of creep is both stress and suction dependent, the higher the wettability of chalk, the larger the amount of creep.

\section{MODEL FORMULATION}

Perzyna's viscoplastic approach (Perzyna, 1964) has been adopted because it is based on a framework similar to that of elastoplasticity, facilitating further time-dependent developments of the elastoplastic Pasachalk model. Various viscoplastic models have been formulated adopting the Bjerrum's notion of equivalent (or reference) time (e.g. Bjerrum, 1967; Borja \& Kavazanjian, 1985; Hickman \& Gutierrez, 2007). Other models have used the concept of the Non Stationary Flow Surface (NSFS) theory (e.g. Nova, 1982; Liingaard et al., 2004). A recent review of the literature is given by Liingaard et al., (2004). The Pasachalk model (Collin et al., 2002) is a cap model with a yield surface composed of three components:

(i) Cam-Clay pore collapse model

The Cam-Clay yield surface is adopted at low stress inclinations, with the following expression:

$f_{1} \equiv I I_{\hat{\sigma}}^{2}+m^{2}\left(I_{\sigma}+\frac{3 c(s)}{\tan \phi_{\mathrm{C}}}\right)\left(I_{\sigma}-3 p_{0}\right)=0$

where $I_{\sigma}$ and $I I_{\sigma}$ are the first and second stress invariants, $c$ is the cohesion, $\phi_{\mathrm{C}}$ is the friction angle in compression path, $p_{0}$ is the apparent pre-consolidation pressure that defines the size of the yield surface and $m$ is a coefficient taking into account the effect of the Lode angle $\beta$. The coefficient $m$ is defined by:

$m=a(1+b \sin 3 \beta)^{n}$

where parameters $a, b$ and $n$ must verify some convexity conditions (Van Eekelen, 1980).

Assuming associated plastic flow, the apparent preconsolidation pressure $p_{0}$ is related to the volumetric plastic strain $d \varepsilon^{\mathrm{vp}}$ following the kinematic equation:

$d p_{0}=\frac{1+e}{\lambda-\kappa} p_{0} d \varepsilon_{v}^{p}$

where $\lambda$ is the compression coefficient and $\kappa$ is the elastic coefficient.

Expression (4) allows both hardening or softening behaviour to be accounted for according to the sign of the volumetric plastic strain. However the softening zone will not be considered here. It can also be 
noted that the irreversible volumetric strain includes the coupled effect of mechanical and suction changes.

\section{(ii) Internal friction model}

In order to formulate a friction model based on a MohrCoulomb type failure criterion with a smoothed plastic surface, Van Eekelen's (1980) formulation has been adopted. It is based on a modification of DruckerPrager's failure cone by introducing a dependence on Lode's angle $\beta$, leading to the following expression of the failure criterion:

$f_{2} \equiv I_{\hat{\sigma}}-m\left(I_{\sigma}+\frac{3 c(s)}{\tan \phi_{\mathrm{C}}}\right)=0$

An associated plasticity is considered also for the friction mechanism.

(iii) Suction effect on yield surface (BBM model) Several phenomena are typical of unsaturated soils:

- The yield stress $p_{0}$ and the material stiffness increase with suction. In BBM this is described by the LC curve, the formulation of which has been adapted for chalk as follows:

$p_{0}(s)=p_{0}(0)+\Delta p_{0} \frac{s}{s+s^{*}}$

where $p_{0}(0)$ is the yield stress for $s=0, \Delta p_{0}$ is the variation of $p_{0}$ between water and oil saturated sample and $s^{*}$ is a parameter controlling the shape of the $L C$ curve.

- Cohesion increases with suction. This is modelled using Eq. (7).

$c(s)=c(0)+k s$

where $k$ is a material constant, $c(0)$ is the cohesion at water saturated state. Note that in chalk, experiments showed that the friction angle is independent of the saturating fluid.

\section{Mechanical elastoviscoplastic model}

Viscous effects in chalk may be observed in triaxial tests performed at various stress rates and/or involving creep stages (Pasachalk2, 2004). The timedependent behaviour of chalk is introduced here based on the elastoviscoplastic approach proposed by Perzyna (1964). Hence, strains are divided into reversible and irreversible parts (related mechanical and suction loading):

$\dot{\varepsilon}_{i j}=\dot{\varepsilon}_{i j}^{m, e}+\dot{\varepsilon}_{i j}^{s, e}+\dot{\varepsilon}_{i j}^{m, v p}+\dot{\varepsilon}_{i j}^{s, p}$

It has been observed that suction variations do not evolve permanent strains. Moreover, it is assumed that reversible strains related to suction are not time-dependent. The following relationship is taken [Alonso et al., 1990]:

$\dot{\varepsilon}_{i j}^{s, e}=\frac{\kappa_{s}}{(1+e)} \frac{\dot{s}}{\left(s+p_{a t}\right)} \delta_{i j}=h_{i j}^{e} \dot{s}$

The stress increment can thus be expressed as follows:

$\underline{\dot{\sigma}}=\underline{\underline{C}}^{e}(s)\left(\underline{\dot{\varepsilon}}^{-\dot{\varepsilon}^{s, e}}-\underline{\dot{\varepsilon}}^{m, v p}\right)$

Since only the irreversible behaviour is timedependent, the elastic moduli of the Pasachalk model can be kept. The values of the moduli defining Hooke's law are recalled in Table 1 . The elastic parameters are suction dependent. The following linear expressions (Pasachalk 2, 2004) have been chosen for the volumetric and shear moduli as a function of suction:

$K(s)=K(0)+k_{s} \cdot s$

$G(s)=G(0)+g_{s} \cdot s$

where $K(0)$ and $G(0)$ are the elastic moduli for a nul suction (water saturated condition), $k_{s}$ and $g_{s}$ are equal to 38 and 66.7 respectively to model the increase of stiffness with the suction.

The irreversible strain may be described as normal to some potential $g$ :

$\underline{\dot{\varepsilon}}^{m, v p}=\gamma\langle\phi(f)\rangle \frac{\partial g}{\partial \underline{\sigma}}$

This formulation is similar to the elastoplastic one, but it is not based on the consistency condition. The amount of strain rate is described with respect to a reference surface $f$, similar to the yield surface. Then, one may define two irreversible mechanisms, one dedicated to the pore collapse mechanism named $f_{c}$, the second one to friction failure named $f_{d}$.

The reference surface $f_{c}$ has the same equation as $f_{1}$ in the Pasachalk model. The reference surface actually represents the elastoplastic yield surface defined based on a hypothetical experiment with an infinitely low strain rate. The function $f_{c}$ may help to define the overstress, as a measure of the amount of the stress state going outside the reference surface.

Table 1. Elastic parameters (Collin et al., 2002).

\begin{tabular}{lcr}
\hline & Water & Oil \\
\hline$K[\mathrm{MPa}]$ & 612 & 726 \\
$G[\mathrm{MPa}]$ & 500 & 700 \\
$E[\mathrm{MPa}]$ & 1180 & 1590 \\
$v[-]$ & 0.18 & 0.14 \\
\hline
\end{tabular}


Concerning the pore collapse mechanism, the creep potential is based on the following equations:

$\left\langle\phi_{c}\left(f_{c}\right)\right\rangle=\left(\frac{p_{0}^{d}}{p_{0}^{v p}}-1\right)^{\alpha_{c}}$

and (Shao et al., 1993):

$\gamma=\omega\left(\frac{I_{\sigma}}{p_{a}}\right)^{\iota}$

where the viscous parameters are: $\gamma$, the fluidity parameter, $\omega, p_{a}$ and $\iota$, the parameters defining the influence of stress on the fluidity parameter and $\alpha_{c}$, the exponent of the visco-plastic strain relation (14).

The parameters defining the yield surface of the elastoplastic model for a stress rate of $10^{-3} \mathrm{MPa} / \mathrm{s}$ are given in the Table 2 . The viscous parameters concern mainly the pore collapse mechanism because the failure criterion is assumed to be time-independent. Hence, only the viscous parameters $\gamma$ (fluidity parameter), the reference surface $f_{c}$ and the exponent $\alpha_{c}$ of visco-plastic strain relation have to be determined.

As shear failure is assumed to be time independent, the reference surface $f_{c}$ related to pore collapse only depends on the apparent viscoplastic preconsolidation pressure $p_{0}^{v p}$. Experiments have shown that the pre-consolidation pressure depended directly on the stress-rate. This relation is not defined directly in the model: the effect of rate dependence comes as a result of the chosen visco-plastic formulation.

The $p_{0}^{v p}$ value and the other viscous parameters have been determined by trial and error process in order to fit isotropic compression tests on saturated chalk (oil and water), with loading rate ranging between $5 \times 10^{-5}$ and $10^{-2} \mathrm{MPa} / \mathrm{s}$ (Pasachalk 2, 2004). Within the assumed loading rate range the final values of all parameters are given in Table 3. Note that, in agreement with the notion of overstress, it is not necessary to chose different values of viscous parameters $(\alpha, \omega, \iota)$ for oil or water saturated samples, as the influence of suction is taken into account through the apparent pre-consolidation pressure.

For intermediate degrees of saturation, the LC curve adopted is similar to that used in the elastoplastic model, using Eq. (6) with $\Delta p_{0}^{v p}=3 \mathrm{MPa}, p_{0}^{v p}(0)=2$

Table 2. Yield surface parameters of the elastoplastic model.

\begin{tabular}{lll}
\hline & Water & Oil \\
\hline Friction angle $\phi\left[^{\circ}\right]$ & 22 & 22 \\
Cohesion $c[\mathrm{MPa}]$ & 1.5 & 2.0 \\
Pre-consolidation $p_{0}[\mathrm{MPa}]$ & 10 & 21 \\
Compressibility index $\lambda$ & 0.195 & 0.195 \\
\hline
\end{tabular}

Table 3. Viscous parameters of the model.

\begin{tabular}{lll}
\hline & Water & Oil \\
\hline Pre-consolidation $p_{0}^{v p}[\mathrm{MPa}]$ & 2 & 5 \\
Parameter $\alpha_{c}$ & 5 & 5 \\
Parameter $\omega$ & $5.110^{-9}$ & $5.110^{-9}$ \\
Parameter $\iota$ & 0,0 & 0,0 \\
\hline
\end{tabular}

MPa et $s^{*}=0.2 \mathrm{MPa}$. It is important to notice that the same value of the compressibility index $\lambda$ has been used for the definition of the hardening law of the viscoplastic model.

\section{ASSESSMENT OF THE VISCOUS PARAMETERS}

One of the major shortcomings associated with Perzyna's approach is the definition of the viscous parameters and of the reference surfaces, which are usually found by a trial and error process and not directly experimentally determined. In order to link more directly the parameters to experimental measurement the results of CRS (Constant Rate of Strain) oedometer compression tests at different strain rates and suction (water or oil saturated, $200 \mathrm{kPa}$ suction and dry samples) are first analysed (Priol, 2005; Priol et al., 2007).

It was observed that for a given suction the yield limit (i.e. apparent pre-consolidation pressure) is a function of the imposed strain rate, as already shown in clays by Leroueil et al. (1985). The following relationship coupling the yield limit and the strain rate proposed by Leroueil appeared to fit reasonably data obtained on Lixhe chalk:

$\log _{10}\left(\sigma_{p}\right)=A+\frac{1}{m^{\prime}} \log _{10}\left(\dot{\varepsilon}_{1}\right)$

where $\sigma_{p}$ is the yield limit, $\dot{\varepsilon}_{1}$ is the strain rate and $A$ and $m^{\prime}$ two material parameters. Table 4 summarizes the values of $A$ and $m^{\prime}$ obtained for Lixhe chalk. Equation (16) describes a linear relationship between yield limit and strain rate in a $\log _{10}\left(\sigma_{p}\right): \log _{10}\left(\dot{\varepsilon}_{1}\right)$ plot. It is worth noting that values of $m^{\prime}$ depends now also on suction (Tab. 4). In other words the slope of the linear relationship (16) increases when suction decreases. This is a new further coupling which extends the original Leroueil's relationship. Equation (16) gives the opportunity to define the size of the reference surface defined as the elastoplastic yield surface based on a hypothetical experiment with an infinitely low strain rate. Considering an extremely low strain rate $\left(10-13 s^{-1}\right)$, the yield stress of the reference surface 
Table 4. Material parameters of Leroueil's law.

\begin{tabular}{llc}
\hline & $A$ & $m^{\prime}$ \\
\hline Water & 4,462 & 9,25 \\
$\mathrm{~s}=200 \mathrm{kPa}$ & 4,516 & 10,9 \\
Oil & 4,451 & 16,66 \\
Dry & 4,499 & 22,2 \\
\hline
\end{tabular}

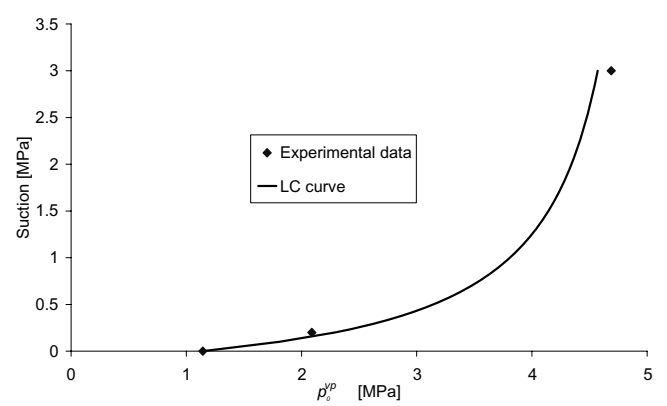

Figure 3. LC curve of the reference surface.

for the different suction conditions could be defined, together with the LC curve of the viscous reference surface (Fig. 3).

Viscous parameters should now to be linked to the $\beta_{i}$ and $\alpha_{c r}$ parameters of equation (1). Figure 2 shows a first discrepancy between the evolution of $\alpha_{c r}$ and the viscous parameters of the model. Indeed Figure 2 does not show a unique relation between $\alpha_{c r}$ and the stress state for the different saturation conditions. On the other hand, it is not necessary to chose different values of viscous parameters for oil or water saturated samples. The influence of suction is only taken into account through the LC curve.

The apparent contradiction can be explained by inspecting Figure 2. One can observe that the creep parameter $\alpha_{c r}$ remains very low up to a threshold that depends on the saturation conditions. Above the threshold, parameters follow a more or less linear relationship with slopes also depending on the saturation conditions. However, if the stress value is normalized with the apparent pre-consolidation pressure of each test as presented in Figure 4, the observed behaviour becomes reasonably independent of the saturation conditions.

It would be interesting to find a direct relationship between the $\alpha_{c r}$ and $\beta_{i}$ parameters of equation (1) and the $\omega$ and $\alpha_{c}$ parameters of the viscous model (Equation 13). Unfortunately, it was not possible to find such a relationship analytically. The main reason is that equation (1) defines the total creep strain and the viscous strain rate is modelled through equation (13). Moreover, the analytical integration of the

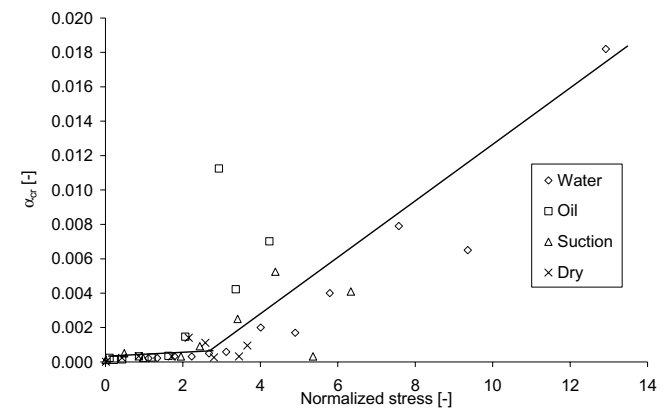

Figure 4. Influence of "normalized" stress level and suction on the creep coefficient $\alpha_{\mathrm{cr}}$ (Priol et al. 2007).

Table 5. Viscous parameters of the model for unsaturated conditions.

\begin{tabular}{ll}
\hline & Water \\
\hline Pre-consolidation $p_{0}^{v p}[\mathrm{MPa}]$ at $\mathrm{s}=0 \mathrm{MPa}$ & 1,143 \\
Parameter $\Delta \mathrm{p}_{0}^{v p}[\mathrm{MPa}]$ & 4 \\
Parameter $\mathrm{s}^{*}[\mathrm{MPa}]$ & 0.5 \\
Parameter $\alpha_{c}$ & 5 \\
Parameter $\omega$ & $5,110^{-9}$ \\
\hline
\end{tabular}

viscous model is not possible for any values of the material parameters.

It was thus decided to keep the first estimation of the two viscous parameters for the modelling of the multi-stage loading tests.

\section{NUMERICAL MODELLING}

Some experimental results obtained by Priol (2005) by running creep oedometer tests under different suction conditions (water saturated, oil saturated and suction equal to $200 \mathrm{kPa}$ ) are reported in Figure 5 in terms of strain versus time curves. One can clearly see in the figure the various loading steps and the creep deformations under different applied stresses.

With the single set of parameters and the proposed visco-plastic model, the three tests have been modelled. Figures 6-8 show satisfactory agreement between experimental data and numerical predictions.

It should be emphasised that, besides creep tests, the collapse experiment can also be modelled by the proposed constitutive law. Indeed, during waterflooding, the suction is decreasing as well as the pre-consolidation pressure following the LC curve. This means that the overstress is growing during waterflooding, leading to an increase of the viscous creep deformation. 


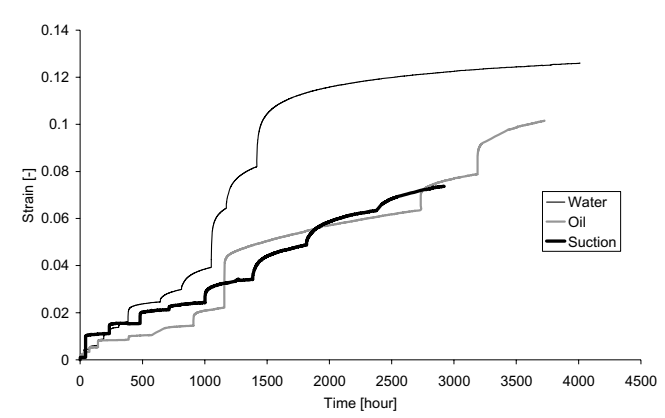

Figure 5. Multiple stage loading tests for different saturation conditions (Priol, 2005).

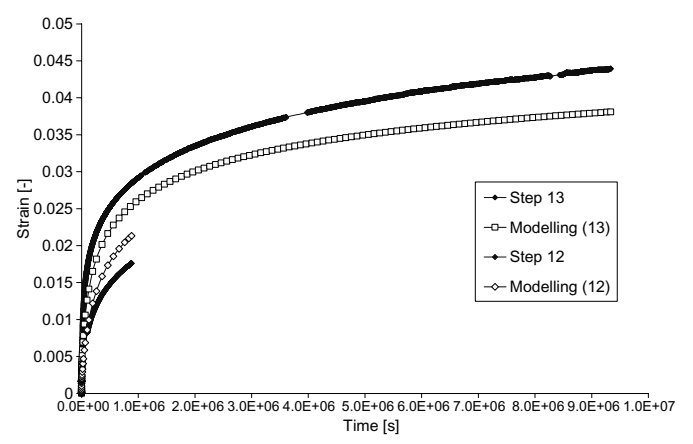

Figure 6. Numerical modeling of creep phase for water saturated chalk samples.

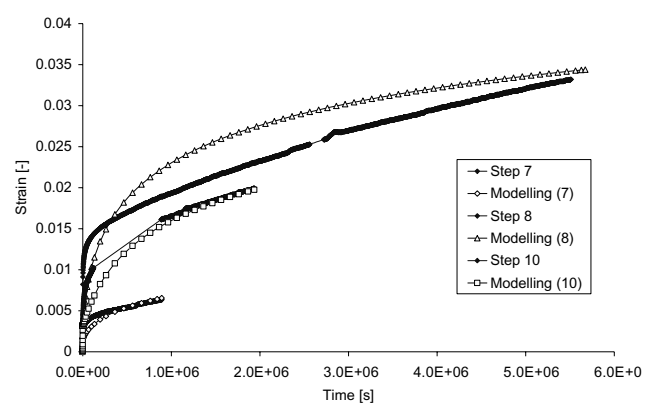

Figure 7. Numerical modeling of creep phase for oil saturated chalk samples.

\section{CONCLUSIONS}

High porosity chalks have a complex mechanical behaviour that depends on chalk porosity, mineralogy, pore fluids, of temperature and of time with

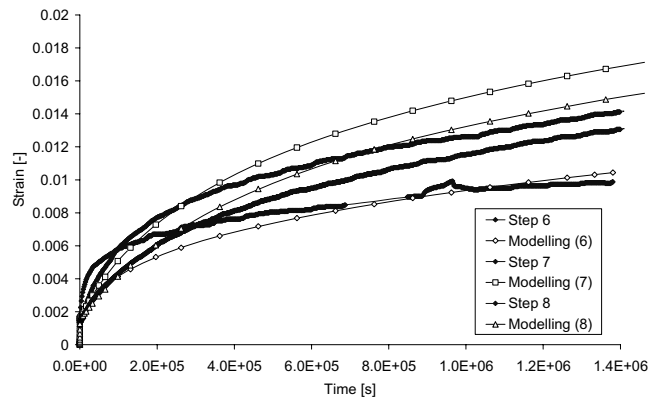

Figure 8. Numerical modeling of creep phase for unsaturated chalk samples $(\mathrm{s}=200 \mathrm{kPa})$.

significant creep deformations. The Pasachalk elastoplastic model (Collin et al., 2002) derived from the Barcelona Basic Model for multiphase reservoir chalk has been extended to account for time effects and creep behaviour as a function of suction.

Some experimental results of multiple stage loading tests carried out on Lixhe chalk under different suction conditions showed that the results obtained under various suctions could be summarized into a single normalized curve.

The relevant viscous parameters of the model were determined based on these experimental results, without using a trial and error method. This has only been possible for the definition of the viscous reference surface. We did not succeed to find an analytical relationship between the parameters of the viscous model and the constitutive law.

By using one single set of parameters, different creep experiments under various suction conditions were simulated, with a satisfactory agreement between experimental data and numerical predictions.

\section{ACKNOWLEDGMENTS}

The authors thank the FNRS for its financial support during the stay of the first author in CERMES.

\section{REFERENCES}

Alonso, E.E., Gens A. and Josa A. 1990. A constitutive model for partially saturated soils. Géotechnique 40 (3): 405-430.

Bjerrum, L. (1967): Engineering geology of Norwegian normally-consolidated marine clays as related to settlement of buildings. Géotechnique, 17: 81-118.

Borja, R.I., Kavazanjian, E. 1985. A constitutive model for the stress-strain-time behaviour of wet clays. Géotechnique, 35 (3): 283-298. 
Collin F., Cui Y.J., Schroeder C. and Charlier R. 2002. Mechanical behaviour of Lixhe chalk partly saturated by oil and water: experiment and modelling. J. Num. Analytical Meth. In Geomechanics, 26, 897-924.

De Gennaro V., Delage P., Cui Y.C., Schroeder Ch. \& Collin F. 2003. Time-dependent behaviour of oil reservoir chalk: a multiphase approach. Soils and Foundations, 43 (4), 131-148.

Delage P., Schroeder C. \& Cui Y.J. 1996. Subsidence and capillary effects in chalks. Proc. EUROCK'96 Conf., vol. 2, 1291-1298, Torino, Italy.

Hermansen H., Landa G.H., Sylte J.E. \& Thomas L.K. 2000. Experiences after 10 years of waterflooding the Ekofisk field, Norway. J. of Petroleum Science and Eng., 26, 11-18.

Hickman, R.J. \& Gutierrez, M.S. 2007. Formulation of a three-dimensional rate-dependent constitutive model for chalk and porous rocks. Int. J. of Numerical and Anal. Meth. in Geomechanics, 31 (4): 583-605.

Leroueil S., Kabbaj M., Tavenas, F. and Bouchard, R. 1985: Stress-strain-strain rate relation for compressibility of sensitive natural clays. Géotechnique 35 (2): 159-180.

Liingaard M., Augustesen P. \& Lade P.V. 2004. Characterization of Models for Time-Dependent Behavior of Soils. Int. J. of Geomechanics ASCE, 4 (3): 157-177.

Nagel N. 2001. Ekofisk geomechanics monitoring, Int. Workshop on Geomechanics in Reservoir Simulation, IFP, Reuil-Malmaison, France.
Nova, R. 1982. A viscoplastic constitutive model for normally consolidated clays. Proc. IUTAM Conf. on Def. and failure of Granular Materials, Delft 1982: 287-295.

Pasachalk2. 2004. Mechanical Behaviour of PArtially and Multiphase SAturated CHALKs Fluid-skeleton Interaction : Main Factor of Chalk Oil Reservoirs Compaction and Related Subsidence, Part 2, Publishable Final report, European contract N ${ }^{\circ}$ ENK6-CT2000-0008, Brussels.

Perzyna, P. 1964. The constitutive equations for rate sensitive plastic materials. Quart. Appl. Mech., 20, 321-332.

Priol G. 2005. Comportement mécanique d'une craie pétrolifère-comportement différé et mouillabilité. $\mathrm{PhD}$ Thesis, Ecole des ponts, Paris.

Priol G., De Gennaro V., Delage P. and Servant T. 2007. Experimental investigation on the time dependent behaviour of a multiphase chalk. Experimental Unsaturated Soil Mechanics, Proc. Physics 112, Springer, T. Schanz (ed.), 161-167.

Shao J.F., Bederiat M. and Schroeder C. 1993. A viscoplastic theory for soft rock behaviour and application. Proc. Geotech. Eng. Hard Soils-Soft Rocks Conf., Balkema.

Van Eekelen H.A.M. 1980. Isotropic yield surfaces in three dimensions for use in soil mechanics. Int. J. Num. and Anal. Meth. in Geomechanics, 4, 98-101. 
